Dikirim: 6 Juli 2015 Diterbitkan: 1 Juni 2016

\title{
Merasa aman karena dianggap normal, kemudahan dan kepasrahan sebagai alasan ibu-ibu memilih persalinan rumah di desa: studi kualitatif di Kalimantan Tengah
}

Feeling safe due to normal antenatal care, easier to going to health facility, and compliance to god decision as reasons for home delivery choice among village mothers: a qualitative study in Central Kalimantan

Aderi Aderi $^{1}$, Yayi Suryo Prabandari ${ }^{2}$, Atik Triratnawati ${ }^{3}$

\begin{abstract}
Purpose: The purpose of this paper was to explore mothers' perceptions of delivery at home in Kartika Bhakti Village, Province of Central Kalimantan. Methods: A case study was conducted involving observations, in-depth interviews and focus group discussion with 7 maternity women, 1 maternity women's husbands, 1 village midwife, 1 community leader and 1 midwife of the village health post in Kartika Bhakti village, Province of Central Kalimantan. Results: The study found six reasons why mothers tended to choose to do delivery at home: barriers to delivery at health facilities; attitudes and preparedness of the midwife to deliver home deliveries; delivery at home benefits; based on the results of the pregnancy examination; not afraid of the risks of delivery; and ready to accept the dangers and risks of delivery. Conclusion: The reasons will be used as a consideration for choosing the birthplace. When the results of a pregnancy examination is good, mothers will tend to choose a home delivery. Furthermore, obstacles in health facilities such as barriers in health centers, geographical, hospital barriers, no postpartum services, and economic abilities are also some of the main reasons to choose to deliver at home. Health education and approaches related to delivery safety need to be improved to change mothers' perceptions.
\end{abstract}

Keywords: perception; labor; giving birth at home

\footnotetext{
${ }^{1}$ Puskesmas Kuala Pembuang II (Email: aderibujang@gmail.com)

${ }^{2}$ Departemen Perilaku Kesehatan, Lingkungan, dan Kedokteran Sosial, Fakultas Kedokteran, Universitas Gadjah Mada

${ }^{3}$ Fakultas Ilmu Budaya, Universitas Gadjah Mada
} 


\section{PENDAHULUAN}

Kematian ibu di dunia setiap tahun kurang lebih 287.000 orang dan mayoritas kematian terjadi di negara berkembang (1). Angka kematian ibu saat melahirkan yang ditargetkan dalam Millenium Development Goals (MDGs) pada tahun 2015 adalah 102 per 100.000 kelahiran hidup (2). Indonesia dianggap belum mampu mengatasi tingginya angka kematian ibu sebesar 307 per 100.000 kelahiran hidup yang berarti setiap tahunnya ada 13.778 kematian ibu atau setiap 2 jam ada 2 ibu hamil, bersalin, nifas yang meninggal karena berbagai penyebab. Kecenderungan perbandingan pada tahun 1990 yang masih 450 per 100.000 kelahiran hidup, menyebabkan target MDGs 125 per 100.000 kelahiran hidup terasa sangat berat untuk dicapai tanpa upaya percepatan (3).

Upaya percepatan untuk menurunkan kematian ibu adalah dengan dengan penempatanmenempatkan bidan di desa-desa, pemerintah serta meluncurkan program pengembangan desa/kelurahan siaga aktif dengan membentuk pos kesehatan desa (poskesdes) di setiap desa. Desa siaga yang dikembangkan sejak tahun 2006 sesuai dengan Keputusan Menteri Kesehatan Nomor 564/Menkes/SK/VIII/2006 tentang Pedoman Pelaksanaan Pengembangan Desa Siaga. Tujuan dibentuknya desa siaga adalah agar masyarakat dapat mengakses dengan mudah pelayanan kesehatan dasar yang memberikan pelayanan setiap hari. Desa siaga merupakan bentuk akselerasi pemerintah terhadap upaya pencapaian MDGs (4).

Riskesdas 2013 mencatat persalinan di Indonesia yang memanfaatkan pada fasilitas kesehatan hanya sebesar 70,4\%. Pemanfaatan fasilitas kesehatan sebagai tempat melahirkan di Provinsi Kalimantan Tengah masih rendah, menduduki peringkat 3 terendah setelah Sulawesi Barat dan Maluku (5). Tempat persalinan non fasilitas kesehatan atau rumah di Indonesia masih tinggi sebesar (29,6\%) (5). Di pedesaan, pada umumnya persalinan dilakukan di rumah, sedangkan di perkotaan kebanyakan di fasilitas kesehatan. Kdi Kalimantan Tengah, jumlah ibu melahirkan di rumah/non fasilitas kesehatan di Kabupaten Seruyan sebesar sebesar 76,89\% (7).

Seruyan Hilir Timur pada tahun 2014 memiliki 111 ibu melahirkan dan 90 dari mereka melahirkan di rumah (81\%). Dari 21 ibu melahirkan di Desa Kartika Bhaki, 20 dari mereka melahirkan di rumah (8).

Perilaku individu ditentukan oleh kepercayaannya. tanpa mempedulikan kepercayaan tersebut sesuai atau tidak dengan pandangan orang lain. Kasus persalinan di rumah, muncul karena cara pandang yang berbeda terhadap kebutuhan kesehatan yang objektif dan subjektif (9). Penelitian ini bertujuan menggali lebih mendalam persepsi ibu terhadap persepsi ibu terhadap bahaya melahirkan di rumah; menggali lebih mendalam persepsi ibu terhadap hambatan melahirkan di fasilitas kesehatan; menggali lebih mendalam persepsi ibu terhadap risiko melahirkan di rumah; dan menggali lebih mendalam persepsi ibu terhadap manfaat melahirkan di rumah.

\section{METODE}

Penelitian ini menggunakan metode kualitatif dengan desain studi kasus. Lokasi penelitian di Desa Kartika Bhakti, Kecamatan Seruyan Hilir Timur, Kabupaten Seruyan, Provinsi Kalimantan Tengah. Subjek penelitian adalah ibu bersalin 1 orang, bidan pos kesehatan desa (poskedes) 1 orang, suami ibu bersalin 1 orang, bidan kampung 1 orang dan tokoh masyarakat 1 orang. Pengumpulan data dilakukan dengan observasi, wawancara mendalam (WM) dan diskusi kelompok terarah (DKT). Penelitian menerapkan tahapan analisis data kualitatif, yaitu data kualitatif yang diperoleh yang semula masih berupa catatan lapangan dan rekaman voice rocorder diubah menjadi bentuk transkrip. Data tersebut kemudian dibaca berulang-ulang, dipelajari, kemudian diidentifikasi bagian terkecil temuan data yang memiliki makna dan melakukan pembuatan kode.

\section{HASIL}

\section{Merasa normal}

Ibu hamil berani memutuskan untuk melahirkan di rumah karena berdasarkan dari hasil pemeriksaan kehamilan yang sehat. Sebagian besar ibu bersalin memutuskan untuk melahirkan di rumah setelah mengetahui kondisi kehamilannya yang sehat, seperti pernyataan ibu bersalin berikut ini :

"Karena di periksa Bu Eka [bidan poskesdes] ibu dan bayinya sehat, tidak ada gangguan dan periksa lagi ke kabupaten [di praktik bidan] ngga papa, ibu dan bayinya sehat alhamdulillah, terus USG ibu dan bayinya juga sehat. Alhamdulillah tekanan darah gini tidak ada penyempitan pinggul istilahnya“ (Ibu bersalin7)

Persepsi tentang bahaya melahirkan di rumah. Ibu bersalin menyatakan bahwa bahaya melahirkan dapat menyebabkan kematian, baik pada ibu maupun bayinya. Ibu bersalin melahirkan di rumah tidak menganggap suatu hal ini menjadi ancaman bagi keselamatan diri dan bayinya, serta dan siap 
menerima konsekuensi dari ancaman yang akan terjadi terhadap persalinan di rumah (10). Jika Dalam persalinan di rumah dan terjadi komplikasi, ibu bersalin akan bersikap pasrah karena kematian sudah ditentukan oleh yang Maha Kuasa, di setiap tempat melahirkan bila Tuhan menghendaki semuanya akan terjadi (11).

"Jika ada bahaya, paling-paling meninggal. Mungkin bayinya meninggal atau ibunya meninggal. Jika waktunya, ya orang akan meninggal. Saya tidak terpikir untuk melahirkan di rumah sakit. Jika bisa dilakukan di rumah. Saya tidak merasa tidak takut dengan kemungkinan macam-macam” (Ibu bersalin6)

"Hambatan utama ke rumah sakit adalah jalan menuju ke sana yang susah, apalagi jalan akan becek jika musim hujan. Tidak mudah untuk memperoleh kendaraan mengantar sampai ke rumah sakit." (Ibu bersalin2)

"Risiko yaa seperti pendarahan tadi kan, jauh kan keterlambatannya kalau mau ke rumah sakit, kalau air ketubannya pecah duluan bayinya belum lahir kan, mau menuju ke rumah sakit kan jauh“ (Ibu bersalin1)

Melahirkan di rumah mendapatkan dukungan dari keluarga, sehingga ibu bersalin bersemangat dan biaya persalinan bisa dicicil.

"ya enak kan ngga banyak orang, 1 keluarga aja... ada keluarga kan, ibarat sakit ngga rame sama orang [di dengar orang lain], bisa sama bidan aja, bidan sama suami [dalam kamar], atau keluarga dalam rumah. Kalau di rumah sakit kan pasti banyak orang lah” (Ibu bersalin3)

Sikap dan kesiagaan bidan melayani persalinan di rumah mencakup 1) bidan selalu ada di tempat atau di rumahnya; 2) siap melayani persalinan 24 jam; 3) bidan mudah dihubungi; 4) memotivasi; 5) rela menunggu; 6) cepat datang ke rumah; 7) bersedia mendatangi; dan 8) ramah melayani persalinan. Sebagian besar ibu bersalin berpendapat bahwa bidan siap dipanggil 24 jam, seperti pernyataan ibu bersalin berikut ini:

“...siap saja, apa namanya 1 x 24 jam, kapan mau melahirkan di jemput mau, pokoknya langsung datang gitu.“(Ibu bersalin6)
Pemeriksaan kehamilan dengan ultrasonografi USG dapat memberikan informasi yang akurat dan memuaskan bagi ibu hamil itu sendiri, sehingga tidak merasa takut dan cemas terhadap kandungannya. Sebagian besar ibu bersalin melakukan USG untuk mengetahui kondisi kehamilannya, seperti pernyataan ibu bersalin berikut ini :

"Kalau di USG kan tau, kan kelihatan bayinya, takutnya kan kalo sunsang bagaimana kan ketahuan... Jadi seringnya USG, kalo diUSG kan enak langsung kelihatan” (Ibu bersalin5)

\section{BAHASAN}

Risiko melahirkan di rumah dapat mengancam jiwa ibu dan bayi, tetapi tidak menganggap suatu ancaman bagi keselamatan diri dan bayinya (10). Melahirkan di rumah dapat terjadi komplikasi persalinan, sehingga harus dirujuk karena ketidakmampuan bidan dalam menangani risiko tersebut.

Jarak antara desa dengan fasilitas kesehatan sangat jauh dan diperburuk dengan kondisi jalan yang rusak, sehingga mempengaruhi waktu tempuh untuk sampai di fasilitas kesehatan (12). Peningkatan jarak $1 \mathrm{~km}$ akan mengurangi kemungkinan melahirkan di fasilitas kesehatan sebesar 4,5\% (13), dan terbatasnya kendaraan roda 4 memengaruhi pemanfaatan fasilitas kesehatan sebagai tempat melahirkan (14). Melahirkan di ranjang rumah sakit adalah pengalaman keterasingan dan ketidakberdayaan yang dihadapkan pada risiko akibat besarnya intervensi (15) dan rawat inap hanya memberikan rasa aman fisik, tetapi tidak memberikan keamanan emosional (16). Selain itu, tingkat ekonomi yang rendah merupakan faktor yang paling dominan yang mempengaruhi pemanfaatan fasilitas kesehatan untuk mendapatkan pelayanan kesehatan (17).

Pilihan melahirkan di rumah adalah suatu penolakan atas rencana yang telah ditetapkan sebelumnya untuk melahirkan di rumah sakit, karena merupakan ancaman dari keyakinan ibu bersalin sendiri (18). Setiap kehamilan membawa risiko bagi ibu dan janin yang dikandungnya. Risiko kehamilan semakin tinggi di negara-negara berkembang, karena dipengaruhi oleh situasi, kondisi dan keadaan umum ibu hamil (19). Ibu bersalin tidak takut dengan risiko yang dapat mengancam keselamatan jiwanya dan bayinya, karena didampingi oleh bidan sebagai penolong persalinan. Pengetahuan dan keahlian bidan dalam mendampingi persalinan akan memberi rasa 
aman terhadap kesulitan yang tak terduga yang bisa timbul saat melahirkan di rumah (20).

Manfaat melahirkan di rumah. Ibu bersalin memilih melahirkan di rumah karena adanya manfaat yang dirasakan seperti ketenangan yang dirasakan ketika melahirkan di rumah (21). Rumah dianggap tempat paling aman untuk melahirkan (22) karena di dalam kamar hanya ada bidan dan suami yang mendampingi. Dukungan keluarga ketika melahirkan di rumah menyebabkan ibu memilih melahirkan di rumah dan menolak untuk melahirkan di fasilitas kesehatan (23).

Hasil pemeriksaan kehamilan, baik dari posyandu, tempat praktik dokter maupun rumah sakit, akan dipergunakan sebagai pertimbangan untuk memilih melahirkan di rumah. Bila kondisi kehamilan sehat, ibu hamil memutuskan melahirkan di rumah karena mempunyai keyakinan dan kemampuan melahirkan secara normal (24).

Bidan poskesdes siap dipanggil atau dihubungi 24 jam oleh keluarga ibu hamil untuk membantu persalinan di rumah. Keluarga ibu hamil bisa menjemput langsung di rumahnya atau menghubungi melalui telepon kepada bidan tersebut. Bidan tidak pernah keberatan dijemput atau dihubungi pada siang hari ataupun malam hari untuk membantu persalinan di rumah. Pengalaman yang didapatkan dari persalinan sebelumnya akan mempengaruhi pemilihan tempat melahirkan selanjutnya (25). Ibu bersalin senang melahirkan di rumah, disebab-kan oleh sikap dan kesiagaan bidan untuk menolong persalinan di rumah.

Pengambilan keputusan tempat melahirkan. Hak perempuan untuk memilih tempat melahirkan berkaitan erat dengan ketersediaan informasi dari hubungan komunikasi dengan tenaga kesehatan profesional (26). Hasil pemeriksaan kehamilan yang sehat, suami, orangtua, mertua dan kerabat akan setuju dan menyerahkan segala keputusan kepada ibu bersalin tersebut untuk memilih tempat melahirkan, seperti pernyataan ibu bersalin berikut ini :

“...sebelumnya ditanyakan kehamilan, bagus-bagus saja, semua bagus sehat keadaannya... orangtuanya juga kan sehat... Misalkan bilangnya mau melahirkan di rumah, di rumah aja, terserah yang penting kan pemeriksaan sehat-sehat semua yang bayinya sehat, ibunya juga sehat ngga ada kendala, ya terserah..." (Ibu bersalin4)

Hasil pemeriksaan yang diperoleh dari tenaga kesehatan adalah faktor penting bagi ibu bersalin dalam pengambilan keputusan tempat melahirkan (27). Bidan mempunyai peranan penting untuk mempengaruhi perempuan dalam pengambilan keputusan tentang pemilihan tempat melahirkan (20). Alasan ibu hamil memanfaatkan pelayanan antenatal adalah untuk mendapatkan saran dan memastikan perkembangan dan keadaan kehamilannya (28). Pemeriksaan kehamilan dengan USG dapat memberikan informasi yang berguna bagi ibu bersalin dalam mencari bidan untuk menyampaikan rencana melahirkan di rumah (29).

\section{SIMPULAN}

Bahaya melahirkan di rumah adalah dapat menyebabkan kematian, baik pada ibu maupun bayinya; hambatan dalam melahirkan di fasilitas kesehatan (hambatan di poskesdes, geografis, hambatan di rumah sakit, waktu melahirkan, tidak ada pelayanan pasca melahirkan, dan kemampuan ekonomi); manfaat dalam melahirkan di rumah (kenal dengan bidan, ada pelayanan pasca melahirkan, bersemangat, ada yang mendampingi, biaya persalinan bisa diangsur. Keputusan memilih melahirkan di rumah, berdasarkan hasil pemeriksaan kehamilan; Bidan poskesdes siap 24 jam untuk membantu persalinan di rumah; Pengambilan keputusan adalah ibu bersalin sendiri dan didukung oleh suami dan keluarganya; dan pemeriksaan kehamilan untuk mengetahui perkembangan janin dan kesehatan ibu hamil.

Ibu bersalin seharusnya menjadi peserta BPJS, karena dalam setiap persalinan normal bisa terjadi komplikasi persalinan dan harus dirujuk ke rumah sakit secepatnya. Dinas Kesehatan perlu melakukan perencanaan program promosi kesehatan dengan strategi pemberdayaan masyarakat dalam mengatasi keterbatasan mobil untuk merujuk ke rumah sakit.

\footnotetext{
Abstrak

Tujuan: Penelitian ini bertujuan menggali lebih dalam persepsi ibu terhadap persalinan di rumah di Desa Kartika Bhakti Kecamatan Seruyan Hilir Timur. Metode: Penelitian ini menggunakan metode kualitatif dengan desain studi kasus untuk menggali lebih detail dan mendalam persepsi ibu melahirkan di rumah. Subjek penelitian adalah 7 orang ibu bersalin, 1 orang suami ibu bersalin, 1 orang bidan kampung, 1 orang tokoh masyarakat, dan 1 orang bidan poskesdes di Desa Kartika Bhakti. Sampel diambil dengan purposive sampling, kemudian
} 
pengumpulan data dilakukan hingga mencapai titik jenuh atau saturasi. Pengumpulan data dilakukan dengan triangulasi metode, yaitu observasi, wawancara mendalam dan diskusi kelompok terarah (DKT). Hasil: Penelitian ini menemukan enam alasan mengapa ibu cenderung memilih untuk melakukan persalinan di rumah: hambatan untuk melahirkan di fasilitas kesehatan; sikap dan kesiapan bidan untuk mengantarkan pulang persalinan; pengiriman di rumah manfaat; berdasar- kan hasil pemeriksaan kehamilan; tidak takut dengan risiko persalinan; dan siap menerima bahaya dan risiko pengiriman. Simpulan: Bila hasil pemeriksaan kehamilan itu baik, ibu akan cenderung memilih persalinan di rumah. Selanjutnya, hambatan dalam fasilitas kesehatan seperti hambatan di puskesmas, geografis, hambatan rumah sakit, tidak ada layanan pasca persalinan, dan kemampuan ekonomi juga merupakan alasan utama untuk melahirkan di rumah. Pendidikan dan pendekatan kesehatan yang terkait dengan keselamatan persalinan perlu ditingkatkan untuk mengubah persepsi ibu.

Kata kunci: persepsi; persalinan; melahirkan di rumah

\section{PUSTAKA}

1. WHO, UNICEF, UNFPA, \& Bank World. Trends in Maternal Mortality: 1990 to 2010. 2012.

2. Kementerian Kesehatan Republik Indonesia. Pedoman Pemantauan Wilayah Setempat Kesehatan Ibu dan Anak 2010. Jakarta.

3. Millennium Development Goals. The Report 2010.

4. Kementerian Kesehatan Republik Indonesia. Keputusan Menteri Kesehatan RI. Nomor 1529/Menkes/SK/ X/2010 tentang Pedoman Umum Pengembangan Desa dan Kelurahan Siaga Aktif. Jakarta:

5. Badan Penelitian dan Pengembangan Kesehatan Republik Indonesia. Riset Kesehatan Dasar 2013. Jakarta.

6. Dinas Kesehatan Provinsi Kalimantan Tengah. Profil Kesehatan Provinsi Kalimantan Tengah 2014. Palangkaraya.

7. Dinas Kesehatan Kabupaten Seruyan. Profil Kesehatan Kabupaten Seruyan 2012. Kuala Pembuang.

8. Puskesmas Kuala Pembuang II. Profil Kesehatan 2014. Pematang Panjang.

9. Sarwono S. Sosiologi Kesehatan: Beberapa Konsep dan Aplikasinya (edisi 4., p. 66) 2004. Gadjah Mada University Press. Yogyakarta.

10. Jackson, M. Dahlen H. \& Schmied V. Birthing Outside the System: Perceptions of Risk amongst Australian Women Who Have Freebirths and High Risk Homebirths. Journal Midwifery. 2012. No. 28. Hal. 561-567.
11. Saeedi Z. A. Tabatabaie M. G. Moudi Z. Vedadhir A.A. \& Navidian A. Childbirt at Home: A Qualitative Study Exploring Perceptions of Risk and Risk Management among baloch Women in Iran. Journal Midwifery. 2013. No. 29. Hal. 44-52.

12. Vallely L. M. Homiehombo P. Vallely A. Homer C. S. E. \& Whittaker A. 2013. Exploring women's Perspectives of Access to Care During Pregnancy and Childbirth: A Qualitative Study from Rural Papua New Guinea. Journal Midwifery. 2013. No. 29. Hal. 1222-1229.

13. Kumar S., Dansereau E. \& Murray C. Does Distance Matter for Institutional Delivery in Rural India? An Instrumental Variable Approach, (45762). Munich Personal RePEc Archive. 2013. No. 45762.

14. Edmonds J. K. Paul M. \& Sibley L. Determinants of Place of Birth Decisions in Uncomplicated Childbirth in Bangladesh: An Empirical Study. Journal Midwifery. 2012. No. 28. Hal. 554-60.

15. Lock L. \& Gib H. 2003. The Power of Place. Journal Midwifery. No. 19. Hal. 132-139. Journal Midwifery. 2003

16. Pitchfort E., Teijlingen E. van Watson V., J, J. T. Kiger A. Ireland J. \& Ryan, M. Choice" and place of delivery: a qualitative study of women in remote and rural Scotland. Journal Quality Safety Health Care. 2009. No. 18. Hal. 42-48.

17. Pearson L. Gandhi M. Admasu K. \& Keyes E. B. User Fees and Maternity Services in Ethiopia. International Journal of Gynaecology and Obstetrics. 2011. No. 115. Hal. 310-315.

18. Dahlen H., Jackson, M. \& Stevens, J. Homebirth, Freebirth and Doulas: Casualty and Consequences of A Broken Maternity System. Journal Women Birth. 2011. No. 24. Hal. 47-50.

19. WHO, UNICEF, UNFPA, Bank W., \& UN 2013. Trends in Maternal Mortality: 1990 to 2013. 2013.

20. Mander R. \& Melender H. L. Choice in Maternity: Rhetoric, Reality and Resistance. Journal Midwifery. 2009. No. 25. Hal. 637-48.

21. Hadjigeorgiou E. Kouta C. Papastavrou E. Papadopoulos I. \& Mårtensson L. B. Women's Perceptions of their Right to Choose the Place of Childbirth: An Integrative Review. Journal Midwifery. 2012. No. 28. Hal. 380-90.

22. Boucher D. Bennett C. McFarlin B. \& Freeze R. Staying Home to Give Birth: Why Women in the United States Choose Home Birth. Journal of Midwifery \& Women's Health. 2009. No. 54. Hal. 119-126

23. Wild K. Barclay L. Kelly P. \& Martins N. 2010. Birth choices in Timor-Leste: A framework for understanding the use of maternal health services in low resource settings. Journal Social Science \& Medicine. 2010. No. 71. Hal. 2038-2045.

24. Sjoblom I. Nordstrom B. \& Edberg A. A Qualitative Study of Women's Experiences of Home Birthin Sweden. Journal Midwifery. 2006. No. 22. Hal. 348-355.

25. Bryanton J. Gagnon A. Johnston C. \& Hatem M. Predictors of Women's Perceptions of the Childbirth Experience. Journal Obstetric Gynecologic \& Neonatal Nursing. 2008. No. 37. Hal. 24-34.

26. Barber T. Rogers J. \& Mars S. The Birth Place Choice Project: Phase One. British Journal of Midwifery. 2006 No. 14. Hal. 609-613.

27. O'Cathain A. Walters S. J. Nicholl J. P. Thomas K. J. \& Kirkham M. Use of Evidence based Leaflets to Promote Informed Choice in Maternity Care: 
Randomised Controlled Trial in Everyday Practice. Journal BMJ (Clinical Research Ed.). 202. No. 324. Hal. 1-5.

28. Magoma M. Requejo J. Campbell O. Cousens S. \& Filippi V. 2010. High ANC Coverage and Low Skilled Attendance in a Rural Tanzanian District: A
Case for Implementing a Birth Plan Intervention. Journal Biomedcentral Pregnancy Childbirth. 2010. No. 10. Hal. 1-12.

29. Cheyney M. J. Homebirth as Systems-Challenging Praxis: Knowledge, Power, and Intimacy in the Birthplace. Journal Qualitative Health Research. 2008. No. 18. Hal. 254-268. 